\title{
Buffy-headed marmosets 10 years on
}

\author{
Stephen F. Ferrari and Sérgio L. Mendes
}

The buffy-headed marmoset Callithrix flaviceps is among the rarest of

Brazil's Atlantic Forest primates and is potentially one of the most endangered by habitat destruction. Rarely seen in captivity, little was known about the species until very recently. Studies carried out during the last 10 years have revealed that these marmosets are not only highly adaptable but are also more widespread than was first thought. There thus seems to be room for cautious optimism for the survival of the species as long as further habitat loss can be minimized.

Endemic to a small area of the Atlantic Forest of south-eastern Brazil (Figure 1), the buffyheaded marmoset Callithrix flaviceps may have the smallest natural range of any South American primate. Rare in the wild and virtually unknown in captivity, even in Brazil, the species has a short history and faces an uncertain future. First described at the turn of the century (Thomas, 1903), C. flaviceps had been recorded only at a dozen localities in the state of Espírito Santo (see Hershkovitz, 1977) before being discovered in eastern Minas Gerais 10 years ago (Mittermeier et al., 1980). The species may also occur in the very north of the state of Rio de Janeiro (Hershkovitz, 1977), although this awaits confirmation.

Given its small geographic range and dependence on arboreal habitats, $C$. flaviceps is one of the primates most seriously affected by the widespread destruction that has progressively decimated the Atlantic Forest during the course of this century (Mittermeier et al., 1982). C. flaviceps populations are now restricted to relatively small, isolated remnants of the original forest, the vast majority of which, like that on the Fazenda Montes Claros in Minas Gerais (now the Estação Biológica de Caratinga (EBC), or Caratinga Biological Station), are privately owned. Mittermeier et al. (1980) were in fact only able to confirm the presence of $C$. flaviceps in one officially protected area, the Nova Lombardia Biological Reserve in Espírito Santo.

The recent history of the species is more promising. A great deal of information on its behaviour and ecology was collected during a long-term field study carried out at Montes Claros, while a detailed survey has identified a further four reserves in which $C$. flaviceps occurs. Local residents are campaigning for the preservation of other forest patches within the species's range and an environmental education programme is now well established in eastern Minas Gerais. The evidence from the field studies indicates that this marmoset is highly adaptable and that, as long as further habitat destruction is minimized and some provision is made for interchange between the remaining populations, there is room for optimism for the long-term survival of the species.

\section{Callithrix flaviceps at Fazenda Montes Claros}

Observations of $C$. flaviceps were begun at Montes Claros shortly after the discovery of the species at this site (Alves, 1986) and a long-term study of the species's behavioural ecology was carried out over a 20-month period between 1984 and 1986 (Ferrari, 1988, 1989). Observations of the marmosets have continued intermittently up to the present day and a further detailed behavioural study is now under way.

The main study at Montes Claros was carried out in a hilly area of secondary forest at the northern extreme of the forest reserve. The 


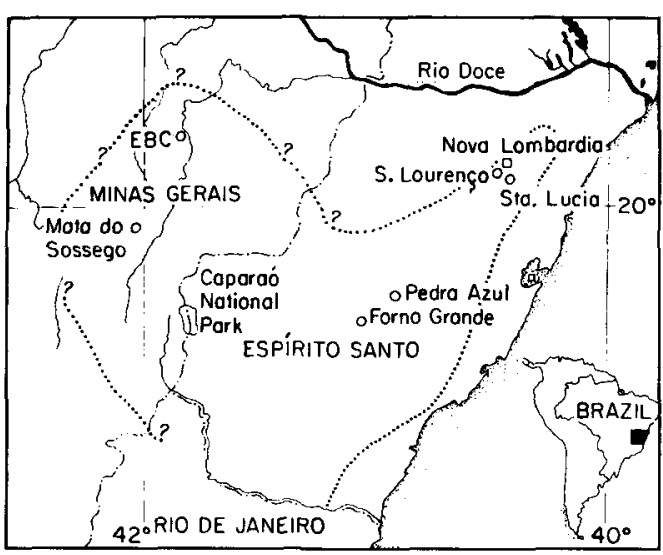

Figure 1. Geographic range of $C$. flaviceps in southeastern Brazil and reserves mentioned in the text.

vegetation is typical of tropical secondary forest, with marked concentrations of relatively few plant species (in comparison with primary forest), many of which are extremely fastgrowing. A plantation approximately 25 years ago, the main area now boasts many native trees of well over $20 \mathrm{~m}$ in height.

Another characteristic of secondary forest, relative to undisturbed habitat, is a paucity of fruit, especially at certain times of the year. This is a result of both the reduction in plant species and the time they require to reach reproductive age. In addition, as the seeds of many colonizing tree species are wind-dispersed, their fruits are generally inappropriate as food for most primates. The monthly monitoring of 1260 trees within the study area between July 1985 and August 1986 revealed that only 222 (17.6 per cent) produced fruit during this period, and that edible fruit was generally scarce except during the wettest months of the rainy season (Ferrari, 1988).

While marmosets require a mixed diet of plant and animal material, they are not dependent on fruit, being able to systematically exploit the edible gums that are produced by many tropical trees and lianas. In addition to their specialized lower incisors, which allow them to gouge gum-producing holes in bark (Coimbra-Filho and Mittermeier, 1977), marmosets exhibit specializations of the digestive tract, which probably allow them to ferment the carbohydrate content of the gum, permit- ting its efficient digestion (Coimbra-Filho et al., 1980).

These adaptations are essential to the survival of marmosets in marginal or impoverished forest habitats. The secondary forest at the Montes Claros study site is dominated by two legume species, Acacia paniculata and Anadenanthera peregrina, both of which produce edible gum and provide the monkeys with an abundant source of plant material. Gum contributed as much as 88 per cent of the records of $C$. flaviceps feeding behaviour during any one month, and accounted for more than half of the feeding records in all months except January and February, when edible fruit was abundant and partially replaced gum in the diet of the study animals.

Complementing their diet with arthropods, especially grasshoppers, and small vertebrates, the marmosets are able to thrive in an environment that appears to be relatively

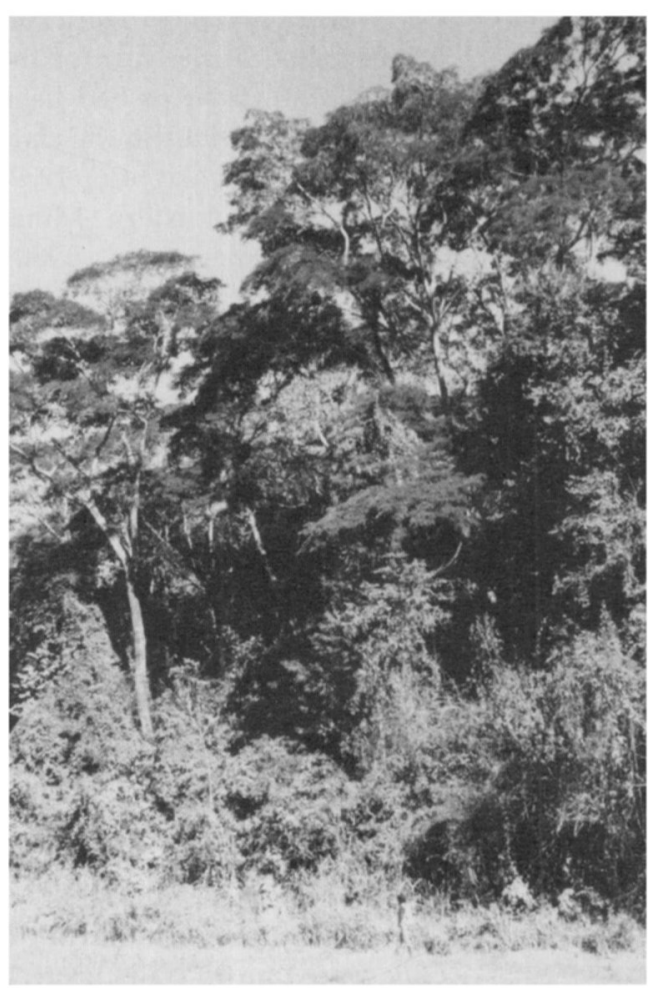

Secondary forest in the C. flaviceps study area at Montes Claros. The large, open-crowned trees are all of a single species, Anadenanthera peregrina. 
inhospitable to other primates. More than 50 muriquis Brachyteles arachnoides are present in the reserve, for example, but have never been observed within the marmoset study area. $C$. flaviceps is the most abundant monkey in this part of the forest, where it forms large, highly stable social groups. Recent observations also indicate that the marmoset population in this area has been expanding over the past 5 years. C. flaviceps appears to be least abundant in the primary forest at Montes Claros. The total $C$. flaviceps population within the reserve at Montes Claros, whose area is approximately 800 ha, was estimated at between 200 and 300 individuals.

\section{Callithrix flaviceps in Espírito Santo and Minas Gerais}

C. flaviceps was registered in a further four protected areas in Espírito Santo: the Biological Stations of São Lourenço and Santa Lúcia (municipality of Santa Teresa), and in the Forestry Reserves of Pedra Azul and Forno Grande (Figure 1). Local residents are also establishing a research station at the Mata do Sossego in Manhuaçú, Minas Gerais, where the marmoset is known to occur. No evidence could be found of the existence of the species in the Caparaó National Park, however.

The survey of $C$. flaviceps distribution in Espirito Santo revealed that the species occurs alongside the white-faced marmoset Callithrix

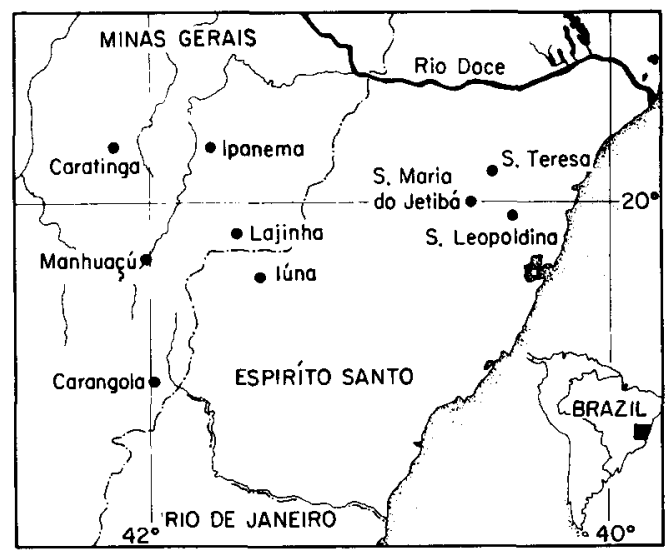

Figure 2. Municipalities in which populations of $C$. flaviceps are known to exist.

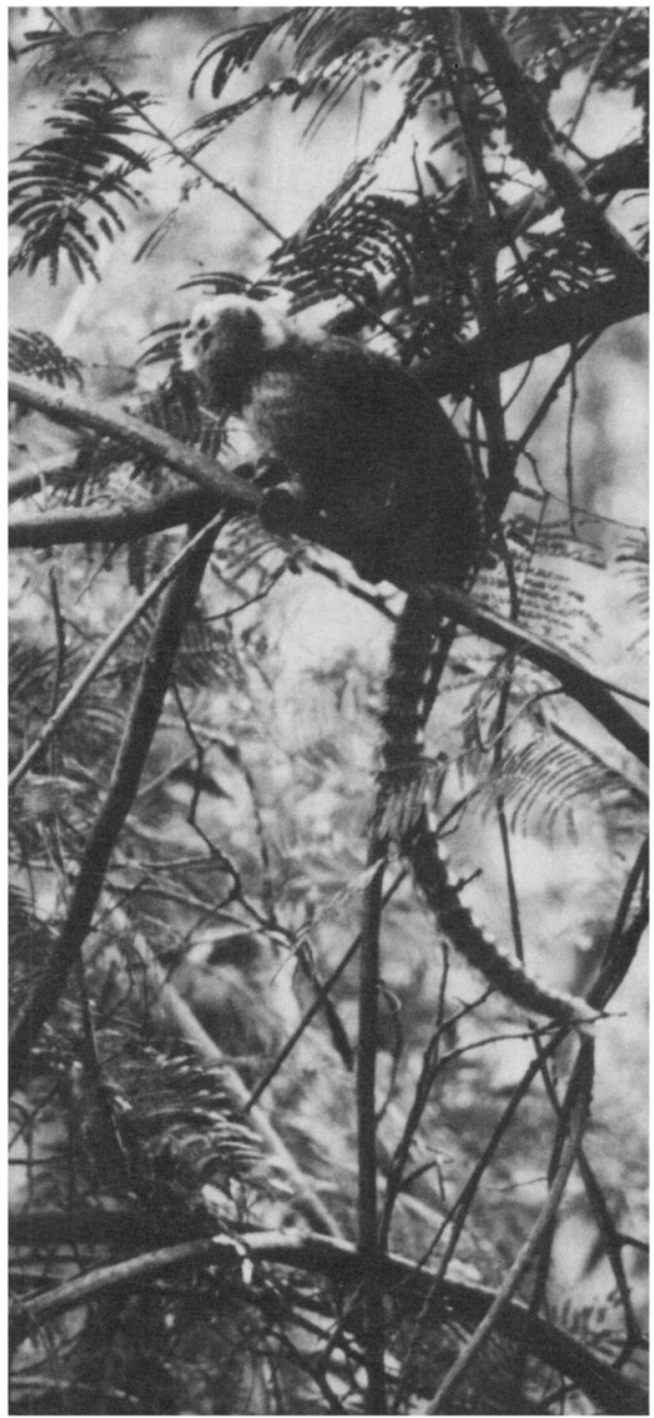

Acacia paniculata is a dietary staple of the marmosets at Montes Claros. Here a female $C$. flaviceps rests between feeding bouts in a typical acacia patch (Stephen F. Ferrari).

geoffroyi in at least three tracts of forest (Santa Lúcia and the Fazenda dos Irmãos Medanha in Santa Teresa, and Rio Bonito in Santa Leopoldina). While the two species are known to hybridize in these areas, they are well differentiated ecologically and species integrity has been maintained despite the isolation of these populations in relatively small tracts of forest. R. A. Mittermeier 
(pers. comm.) also reports seeing greyish individuals, possibly hybrids, in part of the Nova Lombardia Reserve in 1980. Evidence of hybridization between $C$. flaviceps and $C$. aurita was also found in the municipality of Carangola, Minas Gerais. These sites are obviously extremely important for the study of ecological and taxonomic relationships between these three marmoset species.

In addition to the major reserves, buffy-

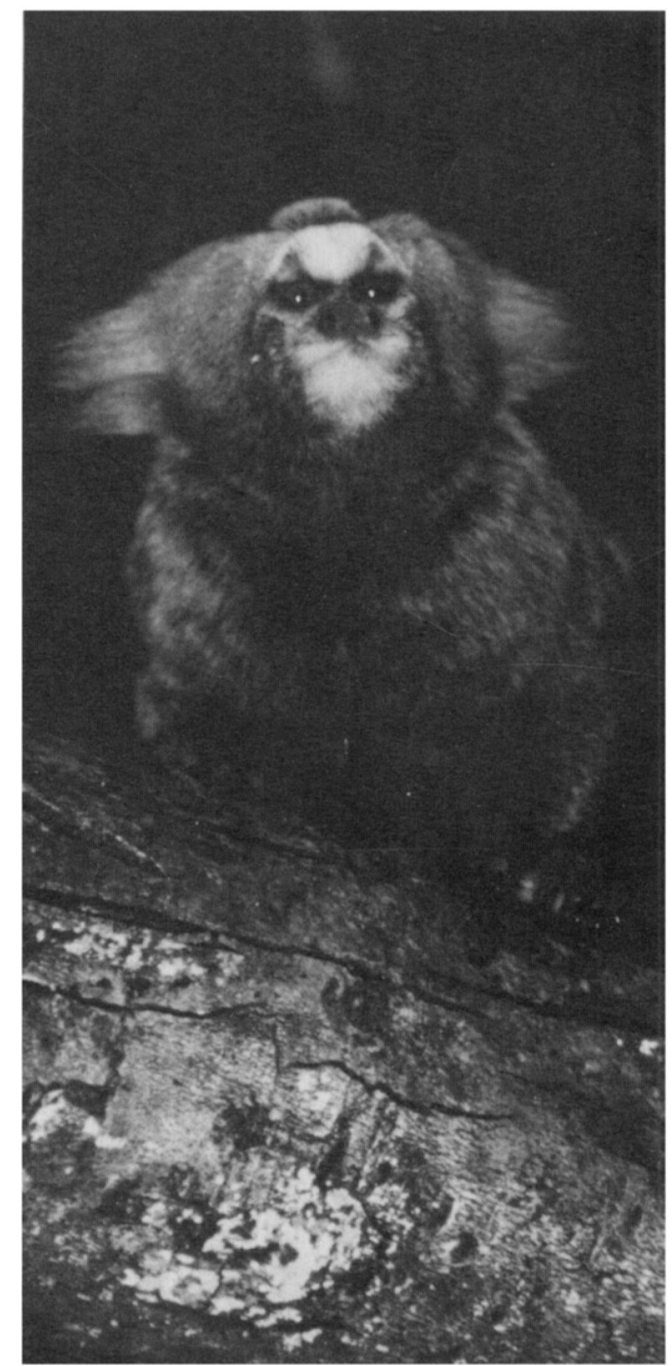

Buffy-headed marmosets have keen vision and are constantly attentive to their surroundings, always on the watch for signs of cryptic insects, especially grasshoppers, which balance the gum in their diet (Stephen F. Ferrari). headed marmosets are known to be present in a number of much smaller forest fragments in the municipalities of Carangola, Caratinga, Ipanema, Lajinha and Manhuaçú in Minas Gerais (Figure 2), and of Iúna, Santa Leopoldina, Santa Maria do Jetibá and Santa Teresa in Espírito Santo, and it seems likely that the species still occurs in other municipalities within the area of its geographical range. The adaptability of $C$. flaviceps was further emphasized during observations at Lajinha, where the marmosets were seen occupying a series of small patches of secondary forest of approximately 1 ha, between which they travelled on open ground over distances of more than $100 \mathrm{~m}$.

\section{0 years on}

Having seen more than 95 per cent of their unique Atlantic Forest ecosystem disappear, many Brazilians are becoming increasingly concerned with the preservation of the forested areas that now remain. Conservation projects, such as those involving the muriqui $B$. arachnoides and the golden lion tamarin Leontopithecus rosalia, have helped to raise public consciousness considerably (Dietz, 1987) and for the preservation of the Atlantic forest, the project S.O.S. Mata Atlântica, is gaining support at all levels of Brazilian society.

While the national parks and other reserves of south-eastern Brazil obviously play an important role in the conservation of this ecosystem and its numerous endemic species of fauna and flora, the preservation of privately owned tracts of forest, however small or disturbed, may also be crucial for many species. As our studies have shown, buffy-headed marmosets are extremely adaptable and are able to thrive under relatively harsh conditions in marginal and secondary forest patches. In the long term, the privately owned forest remnants within the species's range may be extremely important for the maintenance not only of $C$. flaviceps numbers in the wild, but also of the genetic variability of a highly fragmented population. 


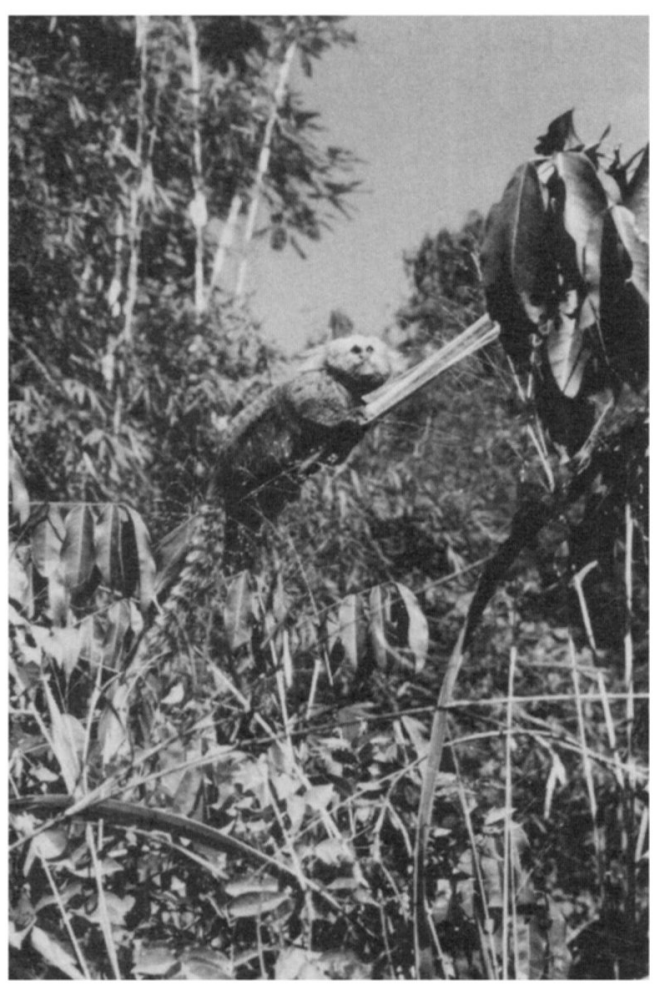

Like other marmosets, C. flaviceps prefer disturbed habitats and forest edge, but are also wary of coming to the ground. This old male is resting on a Piptadenia gonocantha sapling in an abandoned banana plantation, which borders the Montes Claros study site (Stephen F. Ferrari).

\section{Acknowledgments}

Field studies at the Fazenda Montes Claros were authorized by the National Research Council (CNPq) and were supported by the Medical Research Council of Great Britain, the A. H. SchultzStiftung, the Central Research Fund of London University, the Boise Fund and the Leakey Trust. Studies at other sites were supported by the Museu de Biologia Mello Leitão, the WWF-US Primate Programme, FUNCAMP-MB and the A. H. SchultzStiftung. We would like to thank Cida Lopes Ferrari and Russ Mittermeier for their suggestions and Antônio Martins for Figures 1 and 2.

\section{References}

Alves, M.C. 1986. Observações sobre o Callithrix flaviceps (Thomas, 1903) na Estação Ecológica de Caratinga-EBC/FBCN, MG (Callitrichidae, Primates). In A Primatologia no Brasil-2 (ed. M. T. de Mello), pp. 205-206. Sociedade Brasileira de Primatologia, Brasilia.

Coimbra-Filho, A.F. and Mittermeier, R.A. 1977. Tree-gouging, exudate-eating and the 'shorttusked' condition in Callithrix and Cebuella. In The Biology and Conservation of the Callitrichidae (ed. D. G. Kleiman), pp. 105-115. Smithsonian Institute Press, Washington DC.

Coimbra-Filho, A.F., Rocha, N da C. and Pissinatti, A. 1980. Morfofisiologia do ceco e sua correlação com o tipo odontológico em Callitrichidae (Platyrrhini, Primates). Rev. Bras. Biol. 40, 141-147.

Dietz, L.A. 1987. Comparative analysis of speciestargeted conservation education projects. Int. J. Primatol. 8, 442.

Ferrari, S.F. 1988. The behaviour and ecology of the buffy-headed marmoset, Callithrix flaviceps $(O$. Thomas, 1903). PhD Thesis, University College London.

Ferrari, S.F. 1989. Lilliput in the trees. BBC Wildlife, 7, 104-107.

Hershkovitz, P. 1977. Living New World Monkeys (Platyrrhini). Vol. 1. University of Chicago Press, London.

Mittermeier, R.A., Coimbra-Filho, A.F. and Constable, I.D. 1980. Range extension for an endangered marmoset. Oryx, 15, 380-383.

Mittermeier, R.A., Coimbra-Filho, A.F, Constable, I.D., Rylands, A.B. and Valle, C.M.C. 1982. Conservation of primates in the Atlantic Forest of eastern Brazil. Int. Zool. Yrbk, 22, 2-17.

Thomas, O. 1903. Notes on south American monkeys, bats, carnivores and rodents, with descriptions of new species. Ann. Mag. Nat. Hist. 12, $455-464$.

Stephen F. Ferrari, Department of Anthropology, University College London and Departamento de Zoologia, Museu Paraense Emílio Goeldi, Caixa Postal 399, 66.040 Belém, Pará, Brazil.

Sérgio L. Mendes, Museu de Biologia Mello Leitão FNPM, Santa Teresa, Espírito Santo and Instituto de Biologia, Unicamp, Campinas, São Paulo, Brazil. 